\title{
Anxiety and depression after prostate cancer diagnosis and treatment: 5-year follow-up
}

\author{
IJ Korfage*,', M-L Essink-Bot', ACJW Janssens', FH Schröder ${ }^{2}$ and HJ de Koning' \\ 'Department of Public Health, Erasmus MC, University Medical Center Rotterdam, PO Box 1738, 3000 DR Rotterdam, The Netherlands; ${ }^{2}$ Department \\ of Urology, Erasmus MC, University Medical Center Rotterdam, PO Box 1738, 3000 DR Rotterdam, The Netherlands
}

\begin{abstract}
To document anxiety and depression from pretreatment till 5-year follow-up in 299 men with localized prostate cancer. To assess, if baseline scores were predictive for anxiety and depression at I-year follow-up. Respondents completed four assessments (pretreatment, at 6 and 12 months, and at 5-year follow-up) on anxiety, depression and mental health. Respondents were subdivided according to therapy (prostatectomy or radiotherapy) and high vs low-anxiety. Pretreatment $28 \%$ of all patients were classified as 'high-anxiety'; their average anxiety scores decreased significantly post-treatment, that is towards less anxiety. At all assessments, highanxiety men treated by prostatectomy reported less depression than high-anxiety men treated by radiotherapy. Of men treated by radiotherapy, $27 \%$ reported clinical significant levels of depression while $20 \%$ is expected in a general population. The improvement in mental health at 6-months follow-up was statistically significant and clinically meaningful in all respondent groups. Sensitivity of anxiety at baseline as a screening tool was $71 \%$ for anxiety and $60 \%$ for symptoms of depression. We recommend clinicians to attempt early detection of patients at risk of high levels of anxiety and depression after prostate cancer diagnosis since prevalence is high. STAIState can be a useful screening tool but needs further development.

British Journal of Cancer (2006) 94, 1093-1098. doi:I0.1038/sj.bjc.6603057 www.bjcancer.com
\end{abstract}

Published online 4 April 2006

(c) 2006 Cancer Research UK

Keywords: prostatic neoplasms; anxiety; depressive disorder; quality of life; screening; longitudinal studies

Prostate cancer is highly prevalent in most Western countries (Parkin et al, 2001). Prostate cancer can be detected early by PSAtesting, a biologic tumour marker. Radical prostatectomy and external beam radiotherapy are the most commonly used intentionally curative primary therapies.

Being diagnosed with prostate cancer leads to anxiety, but not to the same extent in every patient (Balderson and Towell, 2003; Carlson et al, 2004; Steginga et al, 2004). In a recent study, some $30 \%$ of the participating prostate cancer patients met criteria for general distress in the clinical range (Carlson et al, 2004). In a retrospective, cross-sectional study among men with prostate cancer who were seeking psychological support, the prevalence of severe psychological distress was 37\% (35/94) (Balderson and Towell, 2003). Although several longitudinal studies with a followup longer than 12 months have reported on mental health or emotional well-being after prostate cancer treatment (Potosky et al, 2000; Galbraith et al, 2001; Litwin et al, 2001, 2002; Korfage et al, 2005), the long-term impact of prostate cancer diagnosis and treatment on anxiety and feelings of depression in men is not known.

The high prevalence of severe distress after prostate cancer diagnosis has resulted in the recommendation to target interventions at treatment decision-related distress for all men and to offer in-depth psychological support for those who experience ongoing difficulties (Steginga et al, 2004). Yet, for clinicians and patients it

*Correspondence: IJ Korfage; E-mail: i.korfage@erasmusmc.nl Received 22 November 2005; revised 22 February 2006; accepted 22 February 2006; published online 4 April 2006 would be useful if individual patients at risk of prolonged psychological distress could be identified shortly after diagnosis. To identify high-anxiety men who might need psychological support several instruments have been developed, for example the Memorial Anxiety Scale for Prostate Cancer (MAX-PC) (Roth et al, 2003) or the Hospital Anxiety and Depression Scale (HADS) (Nordin et al, 2001). Results were promising, but follow-up relatively short ( 2 weeks -6 months). We conducted a prospective study with 5-year follow-up in newly diagnosed prostate cancer patients to (1) document the course of anxiety and depression from before the initiation of treatment; and (2) evaluate the predictive accuracy of baseline scores at the individual level for anxiety and depression in the year following diagnosis.

\section{PATIENTS AND METHODS}

\section{Ethics approval and informed consent}

The ethics review committee of the Erasmus MC, the University Medical Center Rotterdam, the Netherlands, approved of the research protocol. All participating men gave written informed consent.

\section{Patients and procedures}

All consecutive newly diagnosed prostate cancer patients from four Rotterdam hospitals were recruited between June 1996 and January 1999. Respondents were diagnosed through the ERSPC screening trial or in a clinical setting. Exclusion criteria were (1) referral to 
watchful waiting or advanced disease therapy; (2) noncompletion of the STAI-State scores (see below), since this score was crucial in assessing the respondents' anxiety level at baseline. The prospective study consisted of four measurements: 1 month before initiation of primary therapy, and at 6 months, 12 months and 5 -year follow-up. The nonrandomly allocated treatment consisted of (intentionally nerve-sparing) radical prostatectomy or external beam radiotherapy (comprising an average of 33 radiation sessions over 7 weeks). Further details on the study design and the inclusion of respondents were published previously (Korfage et al, 2005).

\section{Patients' characteristics}

Information on age, marital status, education, comorbidity and profession was obtained from the respondents. Educational level was classified as low (primary school or lower technical education), intermediate or high (college/university degree). To assess the prevalence of comorbidity, we used a standardized list of 28 chronic conditions, such as heart failure, asthma, diabetes and asked respondents to report which condition they currently experienced or had experienced during the previous year (Dutch Health Interview Survey, Statistics Netherlands).

Baseline clinical information on tumour stage (Hermanek and Sobin, 1992), histopathologic tumour (biopsy) grade and urologic treatment history were obtained from the Regional Cancer Registry. Possible postoperative adjustments to staging in the prostatectomy group were not included to maintain comparability with the radiotherapy group. Data on the clinical or biochemical progression at the 5-year assessment were obtained from the treating physicians. Biochemical recurrence was defined as a PSAlevel of at least $0.2 \mathrm{ng} \mathrm{ml}^{-1}$ after prostatectomy, confirmed at least once, or as a rise in PSA-level of at least $0.5 \mathrm{ng} \mathrm{ml}^{-1}$ after radiotherapy, confirmed at least once.

\section{Psychological measures}

The questionnaires contained three validated self-report psychological measures.

Anxiety was assessed by the State Trait Anxiety Inventory (STAI-State). This scale contains 20 items on, for instance, feeling at ease or upset (Sesti, 2000). Scale scores range from 20 to 80 with higher scores indicating higher levels of anxiety (van der Ploeg et al, 1980). A STAI-State score of more than 44 defines an individual as highly anxious (Spielberger and Vagg, 1984; Millar et al, 1995). Applying this cutoff level, we defined men with pretreatment STAI-State scores equal to or below 44 as 'lowanxiety' and those with scores above 44 as 'high-anxiety'.

The Center for Epidemiologic Studies Depression Scale (CES-D) was used to assess the frequency and severity of symptoms of depression. We applied the 20 -item version with items relating to, for instance, feeling depressed or fearful, being happy, and enjoying life. Scores range from 0 to 60 with higher scores indicating higher levels of symptoms of depression (Radloff, 1977). A score of 16 or higher suggests a clinically significant level of symptoms of depression, which does not necessarily mean that the participant has a clinical diagnosis of depression. In a general population sample, $20 \%$ of the participants had a CES-D score above 16 (Bouma et al, 1995).

The Mental Health scale of the RAND 36-item Short-Form Health Survey (SF36-MH) was used as a general measure of mental health. The scale consists of five items on being nervous, down, peaceful, depressed and happy. Item scores are transformed to ranges of $0-100$ with higher scores indicating better mental health (Ware et al, 1993). Differences of at least 7.9 points are considered clinically meaningful (Norman et al, 2001).

Procedures concerning imputation of missing items were conducted according to the respective guidelines. STAI-State,
CES-D and SF36-MH scores are moderately to strongly correlated ranging at baseline from 0.71 between STAI-State and CES-D to 0.83 between STAI-State and SF36-MH.

\section{Statistical analysis}

Respondents were subdivided into four groups, defined by therapy (surgery or external radiotherapy) and by level of anxiety (high vs low). Between-group and within-group differences in background characteristics and descriptive statistics were calculated using SPSS for Windows, release 10.0 .7 . The $\chi^{2}$ test was used for categorical variables, the $t$-test or Mann-Whitney $U$ for continuous variables. $P$-values $<0.05$ (referring to two-sided statistical tests) were considered significant.

The course of STAI-State, CES-D and SF36-MH scores within therapy groups was analysed by repeated-measures analysis of variance (ANOVA) using proc mixed from the SAS system for Windows release 8.2. Random intercept models were applied that allowed for the use of all available data, including incomplete records. These models comprised the main effects of 'anxiety' and 'time' and the interaction between anxiety and time. Time was included as a factor with four levels - one for each assessment - to account for possible nonlinearities in the course of scale scores. Comorbidity and PSA-level were included in the models as covariates.

To compare the course of anxiety and symptoms of depression in subgroups stratified by baseline anxiety scores, we calculated mean scores at 6 and 12-months follow-up for respondents with low $(\leqslant 44)$ and high $(>44)$ anxiety scores at baseline. To evaluate the diagnostic performance of baseline anxiety screening, we calculated the sensitivity, specificity, positive (PPV) and negative predictive value (NPV) using data of all patients who completed the first three assessments. This complete case analysis is a valid strategy, because missing values at 1-year follow-up were not related to levels of anxiety or symptoms of depression at baseline nor to age.

\section{Age}

Average age differed considerably between treatment groups $( \pm 6$ years). Age-adjustment was not appropriate, because the relation between age and the physical functions in particular was found to be nonlinear (as the decline with ageing was generally steeper for older subjects than for younger ones). Therefore, the average age per treatment group is presented on the $x$-axes in our graphs analogous to earlier reported disease-specific and generic quality of life scores of the same cohort (Korfage et al, 2005).

\section{RESULTS}

\section{Patient's characteristics}

Between June 1996 and January 1999, 415 men met the inclusion criteria, of whom 387 consented to participate and completed the first questionnaire $(93 \%)$. Men who were referred to watchful waiting $(n=25)$ or advanced disease therapy $(n=48)$, or had not completed the STAI-State at the first assessment $(n=15)$ were excluded. The final cohort consisted of 299 primary prostate cancer patients treated with radical prostatectomy $(n=118)$ or external radiotherapy $(n=181)$. The response rate to all four questionnaires was $78 \%$ (214 out of 275 men still alive at the 52 month assessment). Median time to long-term follow-up was 52 months, and mean time 51 months (range: 44-56 months).

Table 1 reports patients' characteristics per treatment group. The table shows that the groups differed significantly in age, the number of comorbid conditions, and the PSA-level before treatment. On the basis of the STAI-State scores at the first assessment, $25 \%$ of the prostatectomy $(n=29)$ and $30 \%$ of the 
radiotherapy group $(n=55)$ were classified as high-anxiety. Characteristics did not differ significantly between high-anxiety and low-anxiety individuals within the two treatment groups, except that in the radiotherapy group the percentage of singles was higher among high-anxiety men compared to low-anxiety men (26\% vs $8 \%, P=0.003)$.

Information on clinical or biochemical recurrence at the 5-year assessment was available for $94 \%$ of the 5-year respondents;

Table I Patient characteristics at baseline

\begin{tabular}{|c|c|c|c|}
\hline & $\begin{array}{l}\text { Prostatectomy } \\
\quad(n=1 \mid 8)\end{array}$ & $\begin{array}{l}\text { Radiotherapy } \\
(n=181)\end{array}$ & P-value \\
\hline Age in years & & & $<0.001$ \\
\hline Average (s.d. range) & $62.6(5.3,50-75)$ & $68.1(5.8,50-82)$ & \\
\hline Educational level (\%) & & & 0.10 \\
\hline Low & $28 \%(31)$ & $38 \%(66)$ & \\
\hline Intermediate & $57 \%(62)$ & $54 \%(94)$ & \\
\hline High & $15 \%(16)$ & $8 \%(14)$ & \\
\hline Marital status (\%) & & & I \\
\hline Married or cohabiting & $87 \%(103)$ & $87 \%(155)$ & \\
\hline Divorced or single & $13 \%(15)$ & $13 \%(24)$ & \\
\hline Comorbidity & & & $<0.001$ \\
\hline Average number of conditions & 0.7 & 1.2 & \\
\hline 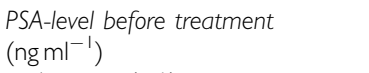 & & & 0.002 \\
\hline Average (s.d.) & $9.7(16.3)$ & $15.7(24.7)$ & \\
\hline Tumour stage before treatment & & & 0.06 \\
\hline $\mathrm{TI}$ & $18 \%(19)$ & $12 \%(20)$ & \\
\hline $\mathrm{T} 2$ & $67 \%(71)$ & $61 \%(103)$ & \\
\hline T3 & $15 \%(16)$ & $27 \%(45)$ & \\
\hline $\mathrm{T} 4$ & - & $1 \%(2)$ & \\
\hline Tumour grade before treatment & & & 0.78 \\
\hline GI & $51 \%(54)$ & $50 \%(86)$ & \\
\hline G2 & $38 \%(40)$ & $37 \%(63)$ & \\
\hline G3 & $11 \%(||)$ & $13 \%(23)$ & \\
\hline
\end{tabular}

prostate cancer had recurred in 5\% (5/91) of the prostatectomy patients and in $21 \%(26 / 123)$ of the radiotherapy patients.

\section{Psychological measures}

Scores of men treated by surgery were more favourable than those treated by radiotherapy for all three psychological measures and at all four assessments, that is, less anxiety and feelings of depression and better mental health.

Pretreatment, $28 \%$ of all patients reported clinical levels of anxiety (STAI-State $>44$ ), that is, $25 \%$ of the surgery group and $30 \%$ of the radiotherapy group. Average STAI-State scores in highanxiety men of 52 (surgery group) and 54 (radiotherapy group) decreased significantly after treatment, that is, less anxiety, and remained at the lower level through follow-up (Table 2). At all assessments, surgically treated high-anxiety men reported less anxiety than high-anxiety men treated by radiotherapy. Repeated measures analysis showed a significantly different score pattern within treatment groups $(P<0.0001)$ : although high-anxiety men improved substantially at 6-months follow-up, they still reported more anxiety than low-anxiety men (Figure 1A).

Compared to pretreatment, all groups except the high-anxiety men treated by radiotherapy reported significantly lower CES-D scores at 6-months follow-up, that is, less symptoms of depression (Table 2). At all assessments, high-anxiety men treated by prostatectomy reported less feelings of depression than highanxiety men after radiotherapy (Table 2). Repeated measures analysis showed that although levels of feelings of depression differed between high- and low-anxiety men, score patterns within treatment groups did not statistically differ (Figure 1B).

At all assessments lower percentages of prostatectomy men reported clinically significant levels of symptoms of depression than the general population $(9-18 \% v s 20 \%)$, pretreatment and at 5 -year assessments in the radiotherapy group these percentages were higher than $20 \%$ (27 and 22\%).

Compared to pretreatment, the improvement in post-treatment SF36-MH was not only statistically significant, but also clinically meaningful (Ware et al, 1993) in all four respondent groups, see Table 2. High-anxiety prostatectomy men reported better mental health than high-anxiety radiotherapy men (Table 2). Repeated measures analysis showed that although levels of SF36-MH differed between high- and low-anxiety men, score patterns within

Table 2 Mean STAI-State, CES-D and SF36-MH by treatment and baseline anxiety level and standard deviation

\begin{tabular}{|c|c|c|c|c|c|c|}
\hline & \multicolumn{3}{|c|}{ Prostatectomy ${ }^{a}$} & \multicolumn{3}{|c|}{ Radiotherapy $^{\mathbf{a}}$} \\
\hline & $\begin{array}{c}\text { High-anxiety }(n=29) \\
\text { Mean (s.d.) }\end{array}$ & $\begin{array}{c}\text { Low-anxiety }(n=89) \\
\text { Mean (s.d.) }\end{array}$ & $\begin{array}{l}\text { All }(n=I \mid 8) \\
\text { Mean (s.d.) }\end{array}$ & $\begin{array}{c}\text { High-anxiety }(n=55) \\
\text { Mean (s.d.) }\end{array}$ & $\begin{array}{c}\text { Low-anxiety }(n=126) \\
\text { Mean (s.d.) }\end{array}$ & $\begin{array}{l}\text { All }(n=\mid 8 I) \\
\text { Mean (s.d.) }\end{array}$ \\
\hline \multicolumn{7}{|c|}{ STAI-State $(80-20)$} \\
\hline $\begin{array}{l}\text { Pretreatment } \\
6 \text { months } \\
12 \text { months } \\
5 \text { year }\end{array}$ & $\begin{array}{c}51.9(7.8) \\
39.2^{b}(12.5) \\
39.1(11.6) \\
40.2(11.3)\end{array}$ & $\begin{array}{r}32.8(7.5) \\
29.8^{\mathrm{b}}(8.4) \\
30.0(8.7) \\
30.5(8.4)\end{array}$ & $\begin{array}{r}37.5(11.2) \\
32.2^{b}(10.3) \\
32.3(10.2) \\
32.8(10.1)\end{array}$ & $\begin{array}{c}54.1(7.7) \\
45.6^{\mathrm{b}}(11.8) \\
42.9(11.4) \\
43.0(10.3)\end{array}$ & $\begin{array}{r}32.8(6.5) \\
30.6^{\mathrm{b}}(8.4) \\
30.6(9.7) \\
31.6^{\mathrm{b}}(9.0)\end{array}$ & $\begin{array}{r}39.1(11.7) \\
34.9^{b}(111.5) \\
34.2(11.6) \\
34.4^{b}(10.5)\end{array}$ \\
\hline \multicolumn{7}{|l|}{ CES-D (60-0) } \\
\hline $\begin{array}{l}\text { Pretreatment } \\
6 \text { months } \\
12 \text { months } \\
5 \text { year }\end{array}$ & $\begin{array}{c}16.8(9.0) \\
13.0^{\mathrm{b}}(12.3) \\
11.6(9.8) \\
10.8(9.7)\end{array}$ & $\begin{array}{r}7.6(5.9) \\
5.9^{\mathrm{b}}(7.1) \\
5.9(6.8) \\
6.1(5.7)\end{array}$ & $\begin{aligned} & 9.9(7.8) \\
& 7.7^{\mathrm{b}}(9.1) \\
& 7.4(10.0) \\
& 7.3(7.0)\end{aligned}$ & $\begin{array}{l}19.9(8.7) \\
17.3(11.0) \\
15.0(10.1) \\
15.5(8.7)\end{array}$ & $\begin{array}{r}8.1(5.8) \\
6.5^{\mathrm{b}}(6.1) \\
6.5^{(}(6.6) \\
7.5^{\mathrm{b}}(7.2)\end{array}$ & $\begin{array}{r}11.2(7.9) \\
9.4^{\mathrm{b}}(8.9) \\
8.9(8.7) \\
9.6^{\mathrm{b}}(8.4)\end{array}$ \\
\hline
\end{tabular}

${ }^{a}$ Differences between anxious and nonanxious groups were $<0.001$ for all scale scores and at all assessments. ${ }^{b}$ Statistically different $(P<0.05)$ from previous assessment. 

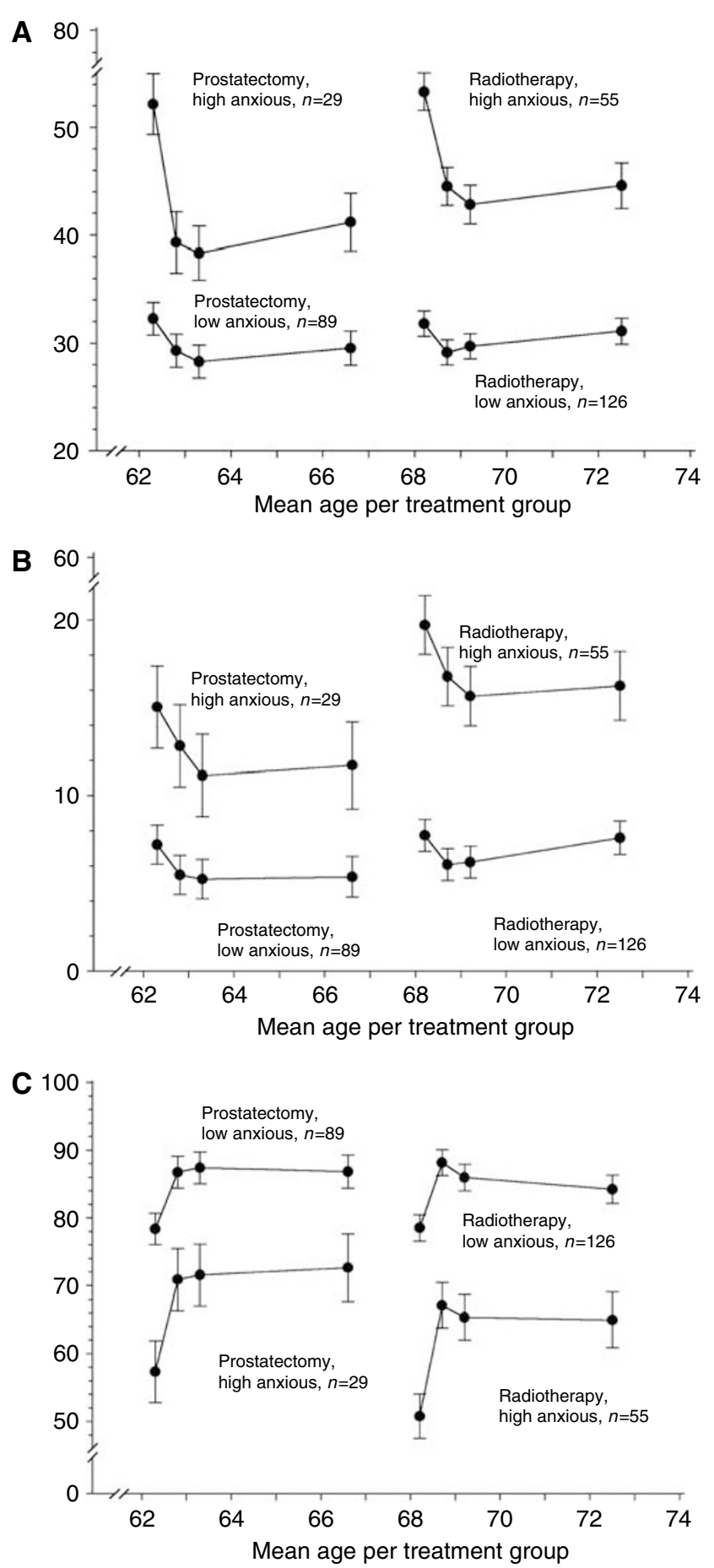

Figure I (A) STAl-State scores during 5-year follow-up by treatment group and baseline anxiety level. (B) CES-D scores during 5-year follow-up by treatment group and baseline anxiety level. (C) SF-36 Mental Health scores during 5 -year follow-up by treatment group and baseline anxiety level.

treatment groups were not significantly different between the groups (Figure 1C).

\section{Predictive value of baseline scores}

Table 3 shows the results of using the STAI-State score at baseline as a screening tool to predict high levels of anxiety and feelings of depression at the 6 and 12-months follow-up. The tool detected
$71 \%$ of the patients who reported high anxiety at 6-months followup (sensitivity $=71 \%$ ), and $60 \%$ of those reporting a clinical level of symptoms of depression (sensitivity $=60 \%$ ). The probability of a high-anxiety score at 6 or 12-months follow-up was $42 \%$ in patients with a high-anxiety score at baseline $(\mathrm{PPV}=42 \%)$, and $8 \%$ in those with low-anxiety scores $(\mathrm{NPV}=92 \%)$. The probabilities of high levels of symptoms of depression at follow-up were $38 \%(\mathrm{PPV}=38 \%)$ and $9 \%(\mathrm{NPV}=91 \%)$ in these groups.

\section{DISCUSSION}

We performed a prospective, longitudinal study on mental health in 299 prostate cancer patients, using validated instruments. At 1 month before treatment roughly one in every four patients was classified as 'high-anxiety'. After 6 months, after initiation of treatment, men reported significantly less anxiety and feelings of depression and a significantly better mental health. Average scale scores remained at the improved levels through follow-up.

Before interpreting the results from a clinical perspective, two methodological issues have to be discussed. First, there is no unequivocal cutoff value for the STAI to define high-anxiety. We used the earlier reported cutoff value of 45 and higher (Millar et al, 1995; Roth et al, 1998) which matches almost perfectly with the validated cutoff value of the HADS (Millar et al, 1995). Second, nonresponse at 5-year follow-up was present. Although, repeated measures analyses can take incomplete cases into account, we excluded the 5-year assessment in evaluating the STAI-State as a screening tool; because the nonresponse at 5-year follow-up was significantly lower in high-anxiety men, a complete case analysis would not be appropriate. Furthermore, it can be argued that a prediction of high-anxiety at 12-months follow-up is clinically more relevant, because high levels of anxiety or symptoms of depression at 5-year follow-up may be unrelated to the preceding prostate cancer diagnosis and treatment.

When we selected an anxiety measure around 1996, validated Dutch versions of both STAI and HADS were available. We needed only one measure and chose STAI, but, in retrospect, we could have chosen HADS as well. We think that in this context there are no really strong scientific arguments to prefer the one to the other. Both are well-validated and commonly used measures for generic anxiety, each with their own strengths and weaknesses. The average STAI-State scores at baseline in the high-anxiety groups, that is, 52 for surgery patients and 54 for radiotherapy, are high in comparison to, for example, the mean STAI-State score in a group of males with anxiety neurosis of 45 (van der Ploeg et al, 1980). Of high-anxiety men, prostatectomy patients reported less anxiety and feelings of depression and better mental health at follow-up than radiotherapy patients. A first possible explanation is that the level of anxiety influenced the treatment decision; high-anxiety men may have perceived surgery as too frightening and therefore opted for radiotherapy. A second explanation could be that surgery led to more reassurance since - contrary to radiotherapy - the prostate actually is removed. Previous research has suggested that men may choose surgery on the basis of the lay belief that surgical removal is the most effective way to cure cancer (Steginga et al, 2002). A third explanation could be age, since high-anxiety radiotherapy men were significantly older than high-anxiety prostatectomy men. However, for a number of reasons, age does not seem to be the explanation. For instance, in spite of the difference in average age low-anxiety men who were treated by radiotherapy reported similar levels of anxiety and symptoms of depression as surgically treated low-anxiety men. Furthermore, several studies reported an association of higher age and lower levels of anxiety. A review study, for instance, reported some evidence that ageing is associated with an intrinsic reduction in susceptibility to anxiety and depression (Jorm, 2000). Furthermore, older men reported better mental health, although higher 
Table 3 Evaluation of baseline anxiety screening for the prediction of psychological distress at follow-up

\begin{tabular}{|c|c|c|c|c|c|c|}
\hline & \multicolumn{2}{|c|}{ Anxiety score at baseline } & Sensitivity (\%) & Specificity (\%) & PPV (\%) & NPV (\%) \\
\hline At 6 months & $12(6 \%)$ & $29(42 \%)$ & 71 & 82 & 42 & 94 \\
\hline At 12 months & $16(8 \%)$ & $26(38 \%)$ & 62 & 80 & 38 & 92 \\
\hline \multicolumn{7}{|c|}{ High-depression score } \\
\hline \multicolumn{7}{|c|}{ High-anxiety or -depression score } \\
\hline At 6 months & $22(11 \%)$ & $34(49 \%)$ & 61 & 83 & 49 & 89 \\
\hline At 12 months & $22(11 \%)$ & $33(48 \%)$ & 60 & 83 & 48 & 89 \\
\hline
\end{tabular}

ages were associated with worse physical health (Litwin et al, 2002). And finally, higher levels of anxiety were found in prostate cancer patients younger than 65 years of age (Lintz et al, 2003). A fourth possible explanation could be that compared to the highanxiety surgery group, a higher percentage of men were 'single' that is, in most cases divorced or widowed - in the high-anxiety radiotherapy group. It has been reported before that marital status contributes to happiness (Joung et al, 1994). A fifth possible explanation could be the higher rate of recurrence in men treated by radiotherapy $v s$ men treated by surgery, that is, $21 v s 5 \%$. Within the radiotherapy group, the recurrence rate did not differ significantly between high- and low-anxiety men.

The frequency of side effects in this same group of patients has been reported elsewhere (Korfage et al, 2005). Four to five years post-treatment, side effects were reported by higher percentages of men treated by surgery than by men treated by radiotherapy, for example, $88 \%$ of erectile dysfunction $v s 64 \%$, and $31 \%$ of urinary leakage $v s 13 \%$. Thus side effects appear not to be the reason for higher anxiety levels in men treated by radiotherapy.

Our findings are in line with a cohort study on 111 prostate cancer patients with 12 months follow-up. Steginga et al (2004) found that psychological and treatment decision-related distress decreased with time, independent of treatment choice. At 12 months follow-up, most men experienced low levels of distress. The authors suggested that, in general, men are resilient to the experience of localized prostate cancer and adjust well psychologically. We agree that the majority of localized prostate cancer patients seem to do fine in the 1-5 years following treatment, but this is not the case for all patients. The challenge for clinicians is to detect those men early who will experience ongoing clinical levels of anxiety and symptoms of depression, and provide those with in-depth support. A (short) anxiety measure could be a useful tool. We applied a 20-item version of the STAI-State. Currently validated 6-item versions are available in English (Marteau et al, 2001) and other languages such as Dutch (van der Bij et al, 2003).

Vedana and co-workers compared the Hospital anxiety and depression scale (HADS) and STAI to identify the most suitable instrument for screening a population at in-hospital intensive rehabilitation on anxiety and depression. The sensitivity of the STAI $(52 \%)$ was less than that of the HADS (72\%), but its specificity (99\%) was greater than that of HADS (84\%). The authors concluded that both instruments can be recommended for psychological screening of patients in an in-hospital intensive rehabilitation (Vedana et al, 2002). A cross-sectional study on psychiatric disorders after successful renal transplantation assessed the value of self-report scales, among others STAI and HADS, in predicting anxiety and depression. HADS was found to significantly $(P=0.003)$ predict anxiety and depression (Arapaslan et al, 2004).

In our study, using the STAI-State baseline score as a screening tool resulted in the early detection of 71 , respectively, $60 \%$ of patients who were to experience high levels of symptoms of anxiety, respectively, feelings of depression at 6 or 12-months follow-up. The sensitivity might be improved by expanding the tool with, for instance, disease characteristics as the Gleason score, or by applying other measures, for instance the HADS (Zigmond and Snaith, 1983).

Treating clinicians may not always realize that, in spite of a comparably favourable prognosis, so many patients experience high levels of anxiety and symptoms of depression after a diagnosis of localized prostate cancer. We recommend clinicians to attempt early detection of patients at risk of such high levels and provide them with psychological support. STAI-State can be a useful screening tool but needs further development.

\section{ACKNOWLEDGEMENTS}

We are grateful to the patients for participating in the study. We thank the departments of urology of the four participating hospitals (Erasmus University Medical Center Rotterdam, St Franciscus Gasthuis, Medical Center Rotterdam Zuid, locations 'Clara' and 'Zuider') for their friendly cooperation. We gratefully acknowledge the Dutch Cancer Society for funding our study (EUR 2000-2329 and EUR 95-11.43).

\section{REFERENCES}

Arapaslan B, Soykan A, Soykan C, Kumbasar H (2004) Cross-sectional assessment of psychiatric disorders in renal transplantation patients in Turkey: a preliminary study. Transplant Proc 36: 1419-1421

Balderson N, Towell $\mathrm{T}$ (2003) The prevalence and predictors of psychological distress in men with prostate cancer who are seeking support. Br J Health Psychol 8: 125-134

Bouma J, Ranchor AV, Sanderman R, van Sonderen E (1995) Het meten van symptomen van depressie met de CES-D [Measuring symptoms of depression using the CES-D]. Rijksuniversiteit Groningen, Noordelijk Centrum voor Gezondheidsvraagstukken: Groningen

Carlson LE, Angen M, Cullum J, Goodey E, Koopmans J, Lamont L, MacRae JH, Martin M, Pelletier G, Robinson J, Simpson JS, Speca M, Tillotson L, 
Bultz BD (2004) High levels of untreated distress and fatigue in cancer patients. Br J Cancer 90: 2297-2304

Galbraith ME, Ramirez JM, Pedro LW (2001) Quality of life, health outcomes, and identity for patients with prostate cancer in five different treatment groups. Oncol Nurs Forum 28: $551-560$

Hermanek P, Sobin LH (1992) TNM Classification of Malignant Tumours. UICC International Union Against Cancers. Berlin: Springer-Verlag

Jorm AF (2000) Does old age reduce the risk of anxiety and depression? A review of epidemiological studies across the adult life span. Psychol Med 30: $11-22$

Joung IM, van de Mheen H, Stronks K, van Poppel FW, Mackenbach JP (1994) Differences in self-reported morbidity by marital status and by living arrangement. Int J Epidemiol 23: 91 -97

Korfage IJ, Essink-Bot ML, Borsboom GJJM, Madalinska JB, Kirkels WJ, Habbema JDF, Schroder FH, de Koning HJ (2005) Five-year follow-up of health-related quality of life after primary treatment of localized prostate cancer. Int J Cancer 116: 291-296

Lintz K, Moynihan C, Steginga S, Norman A, Eeles R, Huddart R, Dearnaley D, Watson M (2003) Prostate cancer patients' support and psychological care needs: Survey from a non-surgical oncology clinic. Psychooncology 12: $769-783$

Litwin MS, Lubeck DP, Spitalny GM, Henning JM, Carroll PR (2002) Mental health in men treated for early stage prostate carcinoma: a posttreatment, longitudinal quality of life analysis from the Cancer of the Prostate Strategic Urologic Research Endeavor. Cancer 95: 54-60

Litwin MS, Melmed GY, Nakazon T (2001) Life after radical prostatectomy: a longitudinal study. J Urol 166: 587-592

Marteau TM, Dormandy E, Michie S (2001) A measure of informed choice. Health Expect 4: 99-108

Millar K, Jelicic M, Bonke B, Asbury AJ (1995) Assessment of preoperative anxiety: comparison of measures in patients awaiting surgery for breast cancer. Br J Anaesth 74: $180-183$

Nordin K, Berglund G, Glimelius B, Sjoden PO (2001) Predicting anxiety and depression among cancer patients: a clinical model. Eur J Cancer 37 $376-384$

Norman GR, Sridhar FG, Guyatt GH, Walter SD (2001) Relation of distribution- and anchor-based approaches in interpretation of changes in health-related quality of life. Med Care 39: 1039-1047

Parkin DM, Bray FI, Devesa SS (2001) Cancer burden in the year 2000. The global picture. Eur J Cancer 37(Suppl 8): S4-66
Potosky AL, Legler J, Albertsen PC, Stanford JL, Gilliland FD, Hamilton AS, Eley JW, Stephenson RA, Harlan LC (2000) Health outcomes after prostatectomy or radiotherapy for prostate cancer: results from the Prostate Cancer Outcomes Study. J Natl Cancer Inst 92: 1582-1592

Radloff LS (1977) The CES-D Scale: A self-report depression scale for research in the general population. Applied Psychological Measurement 1: $385-401$

Roth AJ, Kornblith AB, Batel-Copel L, Peabody E, Scher HI, Holland JC (1998) Rapid screening for psychologic distress in men with prostate carcinoma: a pilot study. Cancer 82: 1904-1908

Roth AJ, Rosenfeld B, Kornblith AB, Gibson C, Scher HI, Curley-Smart T, Holland JC, Breitbart W (2003) The memorial anxiety scale for prostate cancer: validation of a new scale to measure anxiety in men with with prostate cancer. Cancer 97: 2910-2918

Sesti A (2000) State Trait Anxiety Inventory (STAI) in Medication Clinical Trials. Quality of Life Newsletter 25: 16-17

Spielberger CD, Vagg PR (1984) Psychometric properties of the STAI: a reply to Ramanaiah, Franzen, and Schill. J Pers Assess 48: 95-97

Steginga SK, Occhipinti S, Gardiner RA, Yaxley J, Heathcote P (2002) Making decisions about treatment for localized prostate cancer. BJU Int 89: $255-260$

Steginga SK, Occhipinti S, Gardiner RA, Yaxley J, Heathcote P (2004) Prospective study of men's psychological and decision-related adjustment after treatment for localized prostate cancer. Urology 63: 751-756

van der Bij AK, de Weerd S, Cikot RJ, Steegers EA, Braspenning JC (2003) Validation of the dutch short form of the state scale of the Spielberger State-Trait Anxiety Inventory: considerations for usage in screening outcomes. Community Genet 6: 84-87

van der Ploeg HM, Defares PB, Spielberger CD (1980) Validation of the state-traite anxiety inventory (Handleiding bij de zelfbeoordelingsvragenlijst) (in Dutch). Ned T Psychologie 35: 243-249

Vedana L, Baiardi P, Sommaruga M, Galli M, Neri M, Pedretti RF, Tramarin R, Bertolotti G (2002) Clinical validation of an anxiety and depression screening test for intensive in-hospital rehabilitation. Monaldi Arch Chest Dis 58: $101-106$

Ware JEJ, Snow KK, Kosinski M, Gandek BG (1993) SF-36 health survey: manual and interpretation guide. Boston, MA : The Health Institute, New England Medical Center

Zigmond AS, Snaith RP (1983) The hospital anxiety and depression scale. Acta Psychiatr Scand 67: 361-370 